\title{
Synchronization of Chromosome Dynamics and Cell Division in Bacteria
}

\author{
Martin Thanbichler ${ }^{1,2}$ \\ ${ }^{1}$ Max Planck Institute for Terrestrial Microbiology, Karl-von-Frisch-Straße, D-35043 Marburg, Germany \\ ${ }^{2}$ Laboratory for Microbiology, Department of Biology, Philipps University, Karl-von-Frisch-Straße 8, \\ D-35043 Marburg, Germany \\ Correspondence: thanbichler@mpi-marburg.mpg.de
}

Bacterial cells have evolved a variety of regulatory circuits that tightly synchronize their chromosome replication and cell division cycles, thereby ensuring faithful transmission of genetic information to their offspring. Complex multicomponent signaling cascades are used to monitor the progress of cytokinesis and couple replication initiation to the separation of the two daughter cells. Moreover, the cell-division apparatus actively participates in chromosome partitioning and, particularly, in the resolution of topological problems that impede the segregation process, thus coordinating chromosome dynamics with cell constriction. Finally, bacteria have developed mechanisms that harness the cell-cycle-dependent positioning of individual chromosomal loci or the nucleoid to define the cell-division site and control the timing of divisome assembly. Each of these systems manages to integrate a complex set of spatial and temporal cues to regulate and execute critical steps in the bacterial cell cycle.

n recent years, considerable progress has been made in understanding the cell biology of bacteria and, in particular, the organization and dynamics of their chromosomes (Shih and Rothfield 2006; Graumann 2007; Morris and Jensen 2008; Reyes-Lamothe et al. 2008b; Thanbichler and Shapiro 2008). It has emerged that bacterial cells have evolved a variety of mechanisms to closely coordinate replication and segregation of chromosomal DNA with cell division, thus ensuring that genetic information is passed on faithfully. In the absence of these regulatory circuits, premature formation of a division septum can lead to dissection of the nucleoid and generation of anucleate cells. Conversely, untimely origin firing before the end of cell division may result in the accumulation of supernumerary chromosomes, thereby interfering with proper cell cycle and gene regulation, and loading the cell with a substantial metabolic burden. This article first summarizes our current knowledge on checkpoints that couple replication initiation and the last stages of chromosome segregation to the progression

Editors: Lucy Shapiro and Richard Losick

Additional Perspectives on Cell Biology of Bacteria available at www.cshperspectives.org

Copyright (C) 2010 Cold Spring Harbor Laboratory Press; all rights reserved; doi: 10.1101/cshperspect.a000331

Cite this article as Cold Spring Harb Perspect Biol 2010;2:a000331 
M. Thanbichler

of cell constriction. Subsequently, it discusses effects of chromosome dynamics on the temporal and spatial control of divisome assembly.

\section{ORGANIZATION AND DYNAMICS OF CHROMOSOMAL DNA}

Bacteria usually contain a single, circular chromosome that floats freely in the cytoplasm. Although not encased in a specific membrane compartment, it frequently occupies a distinct region within the cell, termed the nucleoid. With an average size of approximately four megabases, the contour length of a chromosome measures approximately $1 \mathrm{~mm}$ and thus exceeds the length of a typical bacterial cell by more than 1000-fold. Apparently, this huge molecule needs to be compacted significantly to fit into the confined space of the cell body. Biochemical and electron microscopic analyses on bacterial chromatin have failed to detect the distinct hierarchical organization seen in eukaryotes. As a consequence, the nucleoid has long been envisioned as a compact tangle of DNA lacking higher-order structure. However, recent studies investigating the localization of individual chromosomal loci within cells from a variety of different species have revealed that the nucleoid in fact has a defined architecture. In all organisms analyzed, chromosomal DNA appears to be arranged in a circular superstructure, in which the subcellular position of each locus is directly reflected by its position on the circular chromosomal map (Teleman et al. 1998; Viollier et al. 2004; Wang et al. 2006b). The underlying principles are still unclear, but current data suggest that the chromosome is organized into numerous compact, supercoiled loops that are lined up like pearls on a necklace (Postow et al. 2004; Thanbichler et al. 2005). Proper temporal and spatial organization of bacterial chromatin is critically dependent on the action of various topological regulators. Bacterial structural maintenance of chromosome (SMC) complexes, for instance, act as molecular clamps that interconnect different DNA regions, thereby maintaining the chromosome in a state compatible with efficient DNA replication and segregation (Britton et al. 1998; Hirano 2006). In addition, every bacterium contains a varying set of small nucleoid-associated proteins, which bend or cross-link DNA, thereby adapting DNA topology to the needs of transcription and other cellular processes (Luijsterburg et al. 2006).

The conserved structure of bacterial chromosomes is a direct consequence of coreplicational DNA segregation. Chromosome replication is usually initiated at a single origin and then proceeds bidirectionally until the two replication forks meet in the terminus region (O'Donnell 2006). Immediately after duplication of the origin region, its two copies are rapidly moved apart by an active mechanism (Gordon et al. 1997; Webb et al. 1998; Viollier et al. 2004), setting the corner stones for the incipient sister nucleoids. As replication proceeds, newly synthesized sister duplexes are instantly separated once they emerge from the replication apparatus (replisome) and stacked on top of the preceding stretches of DNA that have already been deposited in the growing nucleoids, thus maintaining the original ordering of loci (Niki et al. 2000; Viollier et al. 2004; Nielsen et al. 2006; Wang et al. 2006b). Other than in the case of the origin regions, this process is likely to be driven by the pulling forces resulting from DNA recondensation, rather than by a dedicated segregation machinery. During the course of replication, the replisome migrates slowly along the two arms of the compacted chromosome, ending up near the cell-division plane when it reaches the terminus region (Bates 2008; Reyes-Lamothe et al. 2008a). After removal of DNA from the site of constriction, decatenation of the two sister chromosomes, and resolution of chromosome dimers, the cell divides in between the two fully established nucleoids, giving rise to siblings that each carry the full complement of genes present in the mother cell.

\section{COORDINATION OF REPLICATION INITIATION WITH CELL DIVISION}

Although bacterial replication origins differ considerably with respect to their precise architecture, most of them share several common 
features (Zakrzewska-Czerwinska et al. 2007). Importantly, all bacteria investigated require the $\mathrm{AAA}+\mathrm{ATPase}$ DnaA to initiate replisome assembly. On ATP binding, DnaA interacts with conserved motifs at the replication origin, forming an oligomeric nucleoprotein complex that modifies the topology of the origin such as to promote local unwinding of the DNA duplex at a nearby AT-rich sequence (Mott and Berger 2007). Generation of single DNA strands then facilitates loading of the replicative DNA helicase, which in turn recruits the other components of the replication apparatus. The activity of DnaA is controlled by a variety of mechanisms, affecting the nucleotide state, the free concentration, and the cellular abundance of the protein, as well as the accessibility of its binding sites (Kaguni 2006; Leonard and Grimwade 2009). However, the exact contribution of these different pathways to the inactivation of DnaA after replication initiation and to its reactivation at the start of a new cell cycle still remains to be elucidated. Apart from DnaA-binding sites, replication origins usually contain additional functional elements, such as promoters and recognition motifs for the DNA-bending protein IHF (integration host factor), which support the action of DnaA by inducing changes in the superhelicity and architecture of the origin region.

Once the replisome is assembled, each of the two replication forks proceeds at a speed of about 1000 base pairs/second, which means that duplication of a four-megabase chromosome takes about 33 minutes. The generation time of many bacteria, such as Escherichia coli, is considerably shorter than the duration of S-phase. In these cases, replication is initiated more than once in a single cell, giving rise to siblings that inherit already partially duplicated chromosomes (Cooper and Helmstetter 1968; Niki and Hiraga 1998; Nielsen et al. 2007). The regulatory pathways that ensure the proper number of initiation events in organisms with such overlapping cell cycles are largely obscure.

The situation is different in slow-growing bacteria that only perform a single round of replication in the mother cell. A representative of this group is Caulobacter crescentus, an organism that divides asymmetrically into a sessile stalked cell and a motile, flagellated swarmer cell. Whereas the stalked cell initiates chromosome replication immediately after birth, the swarmer cell rests in a replicationally quiescent, G1-like state until it differentiates into a stalked cell and thus continues its cell cycle (Degnen and Newton 1972). C. crescentus has developed an elaborate mechanism to synchronize replication initiation with the physical separation of the two daughter cells (Fig. 1). One of the key players in the underlying control circuit is the two-component response regulator CtrA, a central component of the regulatory network that drives the $C$. crescentus cell cycle (Quon et al. 1996; Laub et al. 2007). On phosphorylation, CtrA interacts with the promoters of about 50 operons, governing the expression of more than 95 genes (Laub et al. 2002). In addition, it binds to five sites in the replication origin, which overlap with the DnaA- and IHF-binding sites, and with a conspicuously AT-rich region that includes a strong promoter implicated in replication control. Mutations in these sites indeed lead to increased initiation frequencies, indicating that $\mathrm{CtrA} \sim \mathrm{P}$ acts as an inhibitor of chromosome replication (Quon et al. 1998; Siam and Marczynski 2000; Marczynski and Shapiro 2002; Siam et al. 2003; Bastedo and Marczynski 2009). Consistently, the levels of CtrA are high throughout most of the cell cycle, whereas they fall sharply during a short interval around the onset of S-phase, concomitant with a peak in the cellular abundance and activity of the replication initiator DnaA (Domian et al. 1997; Gorbatyuk and Marczynski 2005; Collier and Shapiro 2009).

Aside from cell-cycle-regulated transcription of the ctrA gene, phosphorylation and targeted proteolysis are the key factors determining the abundance of active CtrA within the cell (Quon et al. 1996; Domian et al. 1997). Both processes are mediated by complex regulatory cascades, which converge at the singledomain response regulator DivK (Hecht et al. 1995) (Fig. 1A). The phosphorylation state of DivK is controlled by two proteins, the histidine kinase DivJ and the bifunctional histidine kinase/phosphatase PleC (Ohta et al. 1992; 


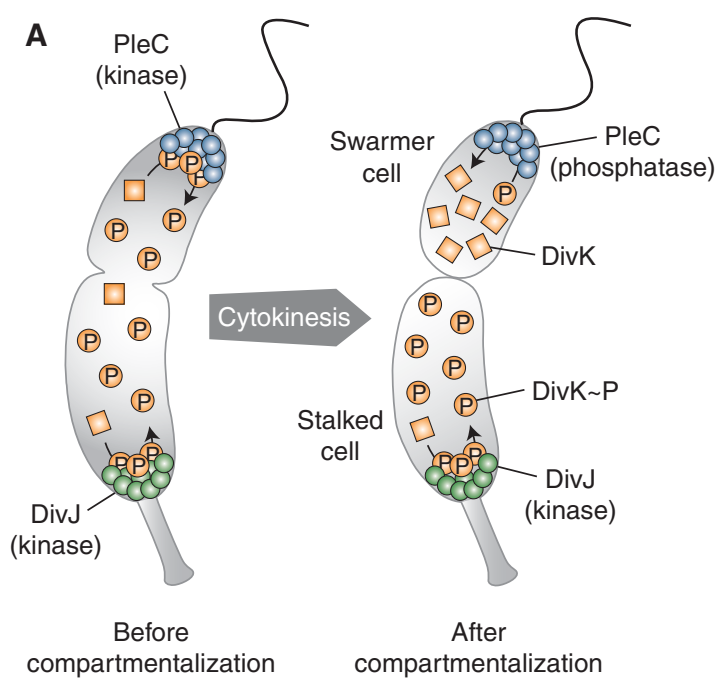

B

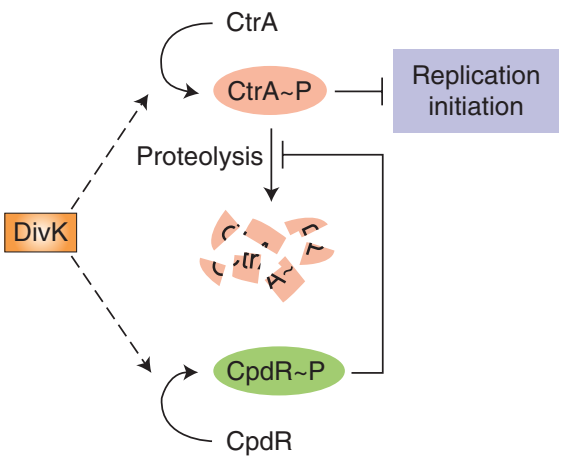

Figure 1. Synchronization of replication initiation with cell division in C. crescentus. $(A)$ Monitoring of cell division via the phosphorylation state of DivK. In dividing cells, the histidine kinase DivJ and the bifunctional histidine kinase/phosphatase PleC form complexes that are localized to the stalked and the flagellated pole, respectively. At this stage, both proteins function as kinases, ensuring a high concentration of DivK $\sim$ P within the cell. After cell division, PleC switches from the kinase to the phosphatase mode. The DivK molecules captured in the swarmer sibling are thus dephosphorylated, whereas those remaining in the stalked sibling are still retained in the phosphorylated state. $(B)$ Role of DivK in the regulation of replication initiation. Dephosphorylated DivK activates a signaling cascade that leads to the phosphorylation of the response regulators $\mathrm{CtrA}$ and $\mathrm{CpdR}$. CtrA $\sim \mathrm{P}$ binds to five sites within the origin of replication, thereby inhibiting replication initiation. Formation of $\mathrm{CpdR} \sim \mathrm{P}$ prevents proteolysis of $\mathrm{CtrA} \sim \mathrm{P}$ and thus reinforces the block of chromosome replication.

Hecht et al. 1995; Wu et al. 1998; Lam et al. 2003; Paul et al. 2008). In stalked cells, Divj and $\mathrm{PleC}$ form complexes that are localized to the stalked and flagellated cell pole, respectively (Wheeler and Shapiro 1999; Jacobs et al. 2001; Viollier et al. 2002; Radhakrishnan et al. 2008). At this stage, both proteins function as kinases, ensuring a high level of DivK $\sim \mathrm{P}$ within the cell (Paul et al. 2008). However, once cytokinesis physically separates the incipient daughter cell compartments, $\mathrm{PleC}$ is switched to the phosphatase mode. As a consequence, the DivK molecules captured in the swarmer sibling are rapidly dephosphorylated, whereas those segregated into the stalked offspring are still retained in the phosphorylated state (Jacobs et al. 2001; Lam et al. 2003; Matroule et al. 2004; Paul et al. 2008).

Nonphosphorylated DivKactivates a phosphosignaling cascade that results in phosphoryl transfer to CtrA (Wu et al. 1998; Biondi et al. 2006) (Fig. 1B). The same pathway phosphorylates and thus inactivates the singledomain response regulator $\mathrm{CpdR}$, a key regulator of targeted CtrA proteolysis (Biondi et al. 2006; Iniesta et al. 2006; Iniesta and Shapiro 2008). Consequently, two complementary pathways ensure accumulation of $\mathrm{Ctr} A \sim \mathrm{P}$ in swarmer cells, allowing it to bind to the chromosomal origin and prevent replication initiation. Once the swarmer cell differentiates into a stalked cell, DivJ replaces PleC at the newly formed stalked pole (Wheeler and Shapiro 1999). The resulting increase in the level of $\operatorname{DivK} \sim \mathrm{P}$ abolishes CtrA and CpdR phosphorylation, thereby inactivating CtrA and triggering its degradation by the ClpXP protease (Iniesta et al. 2006; McGrath et al. 2006). Accordingly, CtrA is cleared from the replication origin, allowing DnaA to initiate replisome assembly. At the same time, elimination of $\mathrm{CtrA} \sim \mathrm{P}$ induces transcription of several essential cell-division genes, 
thereby marking the beginning of the next division cycle (Laub et al. 2002).

Later in the cell cycle, a new PleC cluster is formed at the pole opposite the stalk, again switched to kinase mode and thus stabilizing the DivK P pool (Wheeler and Shapiro 1999; Paul et al. 2008). Because, as a consequence, $\mathrm{CtrA} \sim \mathrm{P}$ levels remain low until the cell reaches the predivisional stage, CtrA-independent mechanisms must be in place to prevent supernumerary initiation events later in S-phase. Consistently, the replisome-associated protein Hda was found to contribute to proper replication control in C. crescentus by inhibiting the activity of DnaA once the first round of DNA synthesis has started (Collier and Shapiro 2009). Given that the replication origins of many $\alpha$-proteobacteria contain CtrA binding sites that overlap elements critical for replication initiation, C. crescentus might not be the only bacterium using CtrA to synchronize its replication and division cycles (Brassinga et al. 2002; Ioannidis et al. 2007; Shaheen et al. 2009).

\section{ROLE OF THE CELL DIVISION PROTEIN FtsK IN CHROMOSOME SEGREGATION}

Sister chromosomes are moved apart in a multistep process, involving active segregation of the newly synthesized origin regions, condensationdriven partitioning of the bulk of the chromosomes, and, finally, separation of the terminus regions. The last step in this cascade can be complicated by several problems. Toward the end of the replication cycle, the terminus regions may become trapped in the closing septum, leading to a block in cell division (Lau et al. 2003). Clearance of the division site is impeded by catenation of the two sister chromosomes, an effect that is routinely observed during replication of circular DNA molecules (Schvartzman and Stasiak 2004). A similar obstacle is formed by chromosome dimers, arising from an odd number of homologous recombination events between two newly synthesized chromosomal regions (Lesterlin et al. 2004). The cell-division apparatus, and in particular its constituent FtsK, play an important role in resolving these issues, thereby coupling cell separation and the final steps of chromosome segregation.

FtsK is a hybrid protein, composed of various functional domains. Its membrane-integral, amino-terminal region $\left(\mathrm{FtsK}_{\mathrm{N}}\right)$ is part of the cell division apparatus and responsible for localization of FtsK to the division site. In E. coli and C. crescentus, $\mathrm{FtsK}_{\mathrm{N}}$ is essential for cytokinesis, probably serving a structural function in divisome assembly (Begg et al. 1995; Liu et al. 1998; Wang and Lutkenhaus 1998; Yu et al. 1998a; Wang et al. 2006a). The soluble, carboxy-terminal part of FtsK $\left(\mathrm{FtsK}_{\mathrm{C}}\right)$, by contrast, is generally dispensable for constriction. It is connected to $\mathrm{FtsK}_{\mathrm{N}}$ via a variable linker and constitutes a molecular motor, belonging to the AAA + ATPase family (Liu et al. 1998; Yu et al. 1998b; Aussel et al. 2002). The motor domains of different FtsK molecules assemble into hexameric rings whose central opening is large enough to accommodate a DNA duplex (Massey et al. 2006). These complexes function as pumps that actively move chromosomal DNA from the constriction site into the daughter cell compartments, reaching translocation rates of up to $7 \mathrm{~kb} / \mathrm{s}$ (Saleh et al. 2004; Pease et al. 2005). To ensure proper sorting of the chromosomes, the cell uses molecular signposts called KOPS (FtsK-orienting polar sequences) (Fig. 2A). KOPS are short, conserved sequence motifs that are highly overrepresented in the genome, with their orientation being skewed toward a defined site (dif) in the terminus region (Bigot et al. 2005; Levy et al. 2005). They are specifically recognized by the $\gamma$-subdomain of FtsK $\mathrm{C}_{\mathrm{C}}$ and thus serve as the preferred loading zones of the translocation complex (Massey et al. 2006; Ptacin et al. 2006; Sivanathan et al. 2006). Their orientation dictates the positioning of $\mathrm{FtsK}_{\mathrm{C}}$ on the DNA molecule and, consequently, the direction of the translocation process, ensuring net movement of $\mathrm{FtsK}_{\mathrm{C}}$ toward the terminus region (Bigot et al. 2006). Although KOPS have initially been identified in E. coli, polarized sequences also appear to guide DNA translocation in other, related systems. The Bacillus subtilis chromosome, for instance, is interspersed with so-called SRS (SpoIIIE recognition sequences), which are required to direct 
M. Thanbichler
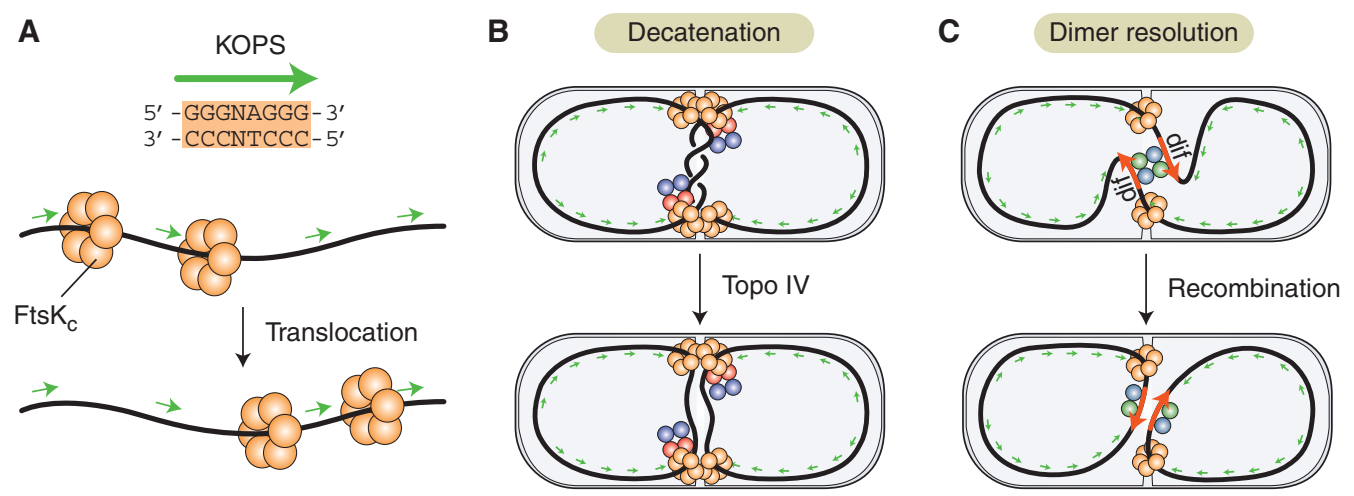

Figure 2. Role of KOPS-regulated DNA translocation by FtsK in the final steps of chromosome segregation. (A) Effect of KOPS (FtsK-orienting polar sequences) on the direction of FtsK movement. The boxed sequence indicates the E. coli KOPS consensus motif. Hexameric rings, assembled from the carboxy-terminal portions of different FtsK molecules $\left(\mathrm{FtsK}_{\mathrm{C}}\right.$ ), load onto DNA in a KOPS-dependent manner, and then translocate in the direction determined by the polarity of the KOPS elements (green arrows). (B) Stimulation of chromosome decatenation by FtsK. Translocation of $\mathrm{FtsK}_{\mathrm{C}}$ toward the terminal dif site positions catenanes at the cell-division plane. Unlinking of the two chromosomes is catalyzed by topoisomerase IV, a tetrameric enzyme composed of the proteins ParC (red spheres) and ParE (blue spheres). FtsK directly interacts with ParC, thereby concentrating the activity of topoisomerase IV to the vicinity of the cell-division site. $(C)$ Role of FtsK in chromosome dimer resolution. The translocase activity of FtsK $\mathrm{C}_{\mathrm{C}}$ moves the two dif sites of a chromosome dimer to the cell-division plane, thereby promoting formation of a productive recombination synapse. In addition, FtsK $\mathrm{C}_{\mathrm{C}}$ directly interacts with the recombinase XerD (green spheres) and thus induces the first pair of strand exchanges. The recombinase XerC (blue spheres) then completes the recombination reaction, restoring the two original chromosomes.

the SpoIIIE-driven import of chromosomal DNA into the nascent forespore at the onset of the sporulation process ( $\mathrm{Wu}$ and Errington 1994; Wu and Errington 1997; Bath et al. 2000; Ptacin et al. 2008).

The pumping activity of FtsK has several implications for chromosome segregation. Sorting of the terminus regions not only clears the division site of DNA but also prevents excessive entanglement of the two sister chromosomes, which may facilitate their distribution to the daughter compartments and their decatenation by topoisomerase (Topo) IV (Adams et al. 1992; Peng and Marians 1993; Zechiedrich and Cozzarelli 1995; Ullsperger and Cozzarelli 1996). In addition to establishing a favorable DNA arrangement, FtsK also affects chromosome decatenation in a direct manner. Topo IV is a heterotetramer composed of two different subunits, named ParC and ParE (Kato et al. 1990). In E. coli and C. crescentus, ParC colocalizes with the replisome, whereas ParE is dispersed within the cell (Espeli et al. 2003b; Wang and Shapiro 2004). Formation of the active enzyme occurs mostly during the late stages of the cell cycle, in a short interval between replication termination and cell separation (Espeli et al. 2003b). FtsK $K_{C}$ was shown to interact with ParC and stimulate Topo IV activity in vitro (Espeli et al. 2003a; Espeli et al. 2003b). It might, therefore, capture ParC after its release from the disassembling replisome and promote interaction between the ParC and ParE subunits, thereby constituting a functional Topo IV complex (Espeli et al. 2003b) (Fig. 2B). This mechanism could allow close temporal and spatial coordination of the processes involved in the final steps of chromosome and cell separation. However, given that decatenation can still occur, albeit inefficiently, in E. coli cells producing a carboxy-terminally truncated form of FtsK, the stimulatory role of $\mathrm{FtsK}_{\mathrm{C}}$ does not appear to be essential for Topo IV activity (Liu et al. 1998; Yu et al. 1998b).

Aside from catenation, dimer formation is a severe impediment to the completion of 
chromosome segregation (Steiner and Kuempel 1998). Cells have evolved a specialized machinery to cope with this problem, consisting of the two tyrosine recombinases XerC and XerD. These proteins cooperate to catalyze a sitespecific recombination event between the two terminal dif sites, thereby restoring the original two chromosomes (Blakely et al. 1993). The DNA translocase activity of FtsK $_{C}$ helps align the two XerCD - dif complexes at the division site and thus promotes the formation of a productive recombination synapse (Fig. 2C). Moreover, it may induce topological changes in the vicinity of dif that are required for proper recombination (Perals et al. 2000; Aussel et al. 2002; Capiaux et al. 2002; Ip et al. 2003; Massey et al. 2004). Apart from its role in synapse formation, FtsK $_{C}$ was shown to interact directly with XerD and thereby stimulate XerD to perform a first pair of strand exchanges, resulting in the generation of a Holliday junction. This intermediate is subsequently converted to a crossover by a second pair of strand exchanges, catalyzed by XerC in an $\mathrm{FtsK}_{\mathrm{C}}$-independent manner (Grainge and Sherratt 1999; Barre et al. 2000; Aussel et al. 2002; Massey et al. 2004; Yates et al. 2006). Given that successive rounds of XerCD-mediated recombination can unlink catenated DNA molecules in vitro, FtsK may also have a direct role in chromosome decatenation that is independent of its interaction with Topo IV (Ip et al. 2003; Grainge et al. 2007). Interestingly, dif recombination requires a closing septum and only occurs shortly before cell division (Steiner and Kuempel 1998; Kennedy et al. 2008). Thus, an increase in the local concentration of FtsK, resulting from constriction of the divisome, might be required for DNA translocation and efficient stimulation of XerCD activity.

\section{ROLE OF NUCLEOID OCCLUSION IN THE REGULATION OF CELL DIVISION}

In most bacteria, the cell division apparatus comprises more than 15 different proteins, which assemble into an annular structure at the future division site. The fundament of this complex machinery is a ring-shaped polymer formed by the tubulin homolog FtsZ (Bi and Lutkenhaus 1991; Lowe and Amos 1998; Mukherjee and Lutkenhaus 1998; Li et al. 2007). The FtsZ ring recruits, directly and indirectly, all other components of the divisome, and its constriction is thought to provide a major driving force for the subsequent division process (Goehring and Beckwith 2005; Osawa et al. 2008). Reorganization of the FtsZ ring is facilitated by its rapid turnover kinetics, with subunits being exchanged at a half-time of only a few seconds (Anderson et al. 2004; Thanedar and Margolin 2004; Peters et al. 2007). Owing to its central role in cytokinesis, FtsZ is the primary target of pathways regulating cell division in bacteria.

Many organisms use a dual mechanism to control divisome positioning and assembly, involving both the Min system and nucleoid occlusion (Fig. 3). In E. coli, the Min system is composed of three proteins, encoded by the minCDE operon (de Boer et al. 1989). It establishes an autonomous oscillatory system that confines the FtsZ polymerization inhibitor MinC to the cell poles, thus limiting assembly of the divisome to the midcell region ( $\mathrm{Hu}$ and Lutkenhaus 1999; Hu et al. 1999; Raskin and de Boer 1999a; Raskin and de Boer 1999b; Hale et al. 2001; Rothfield et al. 2005). B. subtilis and other Gram-positive bacteria, by contrast, use a different variant of the Min system, which does not produce pole-to-pole oscillations but stably tethers $\mathrm{MinC}$ at the latedivision septum and the cell poles (Cha and Stewart 1997; Edwards and Errington 1997; Marston et al. 1998; Bramkamp et al. 2008; Gregory et al. 2008; Patrick and Kearns 2008). In mutants lacking the Min system, division septa are formed randomly within the DNAfree regions of the cell, but never on top of nucleoids (Marston et al. 1998; Yu and Margolin 1999). This phenomenon, termed nucleoid occlusion, indicates a negative effect of chromosomal DNA on FtsZ ring assembly (Mulder and Woldringh 1989; Woldringh et al. 1990; Margolin 2001). Its mechanistic basis lies in the activity of DNA-associated proteins, such as SlmA from E. coli and Noc from B. subtilis, that act as inhibitors of FtsZ polymerization (Wu and Errington 2004; Bernhardt and de 
M. Thanbichler

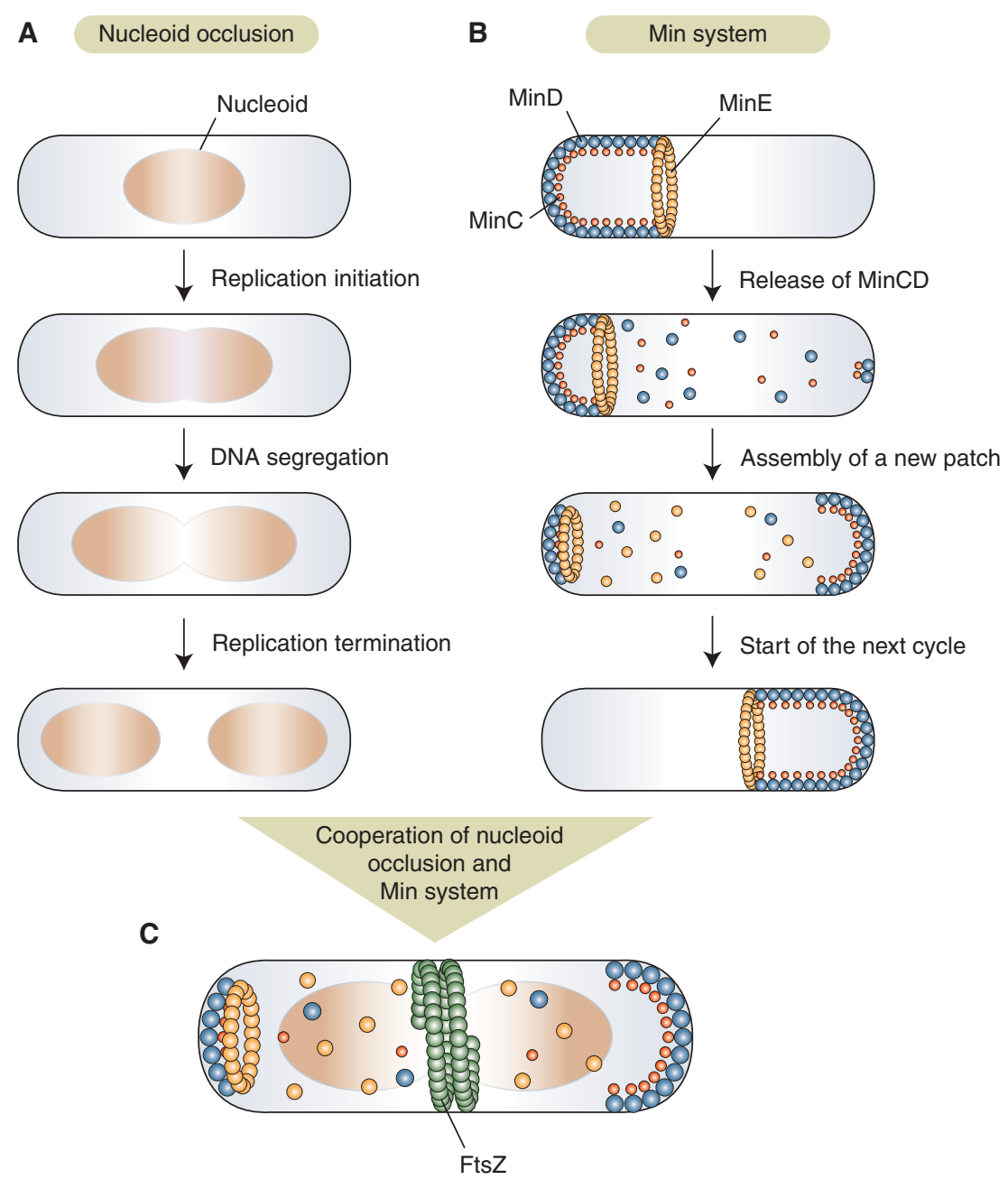

Figure 3. Model for the positioning of the FtsZ ring by the nucleoid occlusion and Min systems in E. coli. (A) Temporal and spatial regulation of cell division by nucleoid occlusion. The nucleoid occlusion protein SlmA preferentially associates with the pole-proximal regions of the nucleoid. At the beginning of the division cycle, the longitudinal dimensions of the nucleoid are small, thereby placing SlmA close to midcell and blocking FtsZ ring assembly. In the course of chromosome replication and segregation, the two nascent daughter nucleoids move apart. As a consequence, the midcell region is cleared of SlmA, allowing FtsZ polymerization to occur. (B) Inhibition of polar cell-division events by the Min system. MinD, bound to the cell division inhibitor MinC, assembles on the cytoplasmic membrane, forming a cap-like polymeric layer that prevents FtsZ ring formation in the polar region of the cell. MinE is organized into a ringshaped structure that gradually displaces MinCD from the membrane. Free MinC and MinD subunits reassemble at the opposite cell pole, thus establishing a new polar cap and restarting the cycle. $(C)$ Cooperation of the nucleoid occlusion and Min systems. The combined action of SlmA and the Min system targets the FtsZ ring to midcell and ensures that divisome formation is delayed to the final phase of the replication cycle. 
Boer 2005). In the absence of these factors, Mindeficient cells accumulate clusters of FtsZ that overlap with the nucleoid and, under certain conditions, initiate cell-division events that lead to bisection of the chromosome. Thus, nucleoid occlusion may have evolved as a safeguard mechanism to protect DNA against guillotining during cytokinesis.

Although evolutionarily unrelated, SImA and Noc both contain a helix-turn-helix DNAbinding domain. In addition, both proteins display similar localization patterns, as they concentrate predominantly in the pole-proximal regions of the nucleoid ( $\mathrm{Wu}$ and Errington 2004; Bernhardt and de Boer 2005). In B. subtilis, this uneven subcellular distribution could be attributed to a skew in the distribution of Noc binding sites. Noc interacts specifically with a conserved 14-base pair sequence, from which it spreads laterally into the flanking chromosomal regions, thereby amplifying the amount of protein associated with the nucleoid (Wu et al. 2009). About 70 copies of this recognition motif are found in the genome, but none of them are located in the terminal quarter of the chromosome. Integration of ectopic binding sites in the terminus region causes a delay in cell division, suggesting that the asymmetric positioning of Noc is important for the timing of divisome formation ( $\mathrm{Wu}$ et al. 2009). Noc might only be able to block the midcell region efficiently in early S-phase, when the nucleoid is small and its Noc-associated regions are in proximity to each other. However, once chromosome replication and segregation have started, expansion of the nucleoid likely displaces the majority of Noc from the cell center. As a consequence, divisome assembly may be allowed to initiate before the two daughter nucleoids are actually fully separated, facilitating closure of the septum immediately after completion of the replication cycle (Wu et al. 2009). The mechanism whereby SImA and Noc affect divisome assembly is still unclear. SlmA can recruit FtsZ to the nucleoid when overproduced and promote bundling of FtsZ filaments in vitro. It could, therefore, act by out-competing other cell-division proteins that associate with and stabilize the FtsZ ring (Bernhardt and de Boer 2005).

\section{CONTROL OF DIVISION SITE PLACEMENT BY THE SPATIAL REGULATOR MipZ}

There are a number of bacteria that divide by medial fission, even though they lack the Min and nucleoid occlusion systems, suggesting the existence of alternative mechanisms for the control of divisome assembly. Work in C. crescentus has indeed identified a novel cell-division regulator, designated MipZ, which couples the positioning and assembly of the FtsZ ring to the initiation of chromosome replication and the bipolar positioning of the two sister origin regions (Thanbichler and Shapiro 2006). MipZ is a member of the Walker A cytoskeletal ATPase (WACA) family (Michie and Lowe 2006) and highly conserved among $\alpha$-proteobacteria. Its function is critically dependent on the DNAbinding protein ParB, which acts as a central regulator of chromosome dynamics in bacteria (Thanbichler 2009). In C. crescentus, ParB recognizes four conserved sites ( $p a r S$ ) in the vicinity of the chromosomal origin of replication (Mohl and Gober 1997; Figge et al. 2003). After initial site-specific binding, it spreads laterally into the neighboring chromosomal regions and forms a centromer-like nucleoprotein complex that cooperates with the DNA-partitioning protein ParA to actively separate the newly synthesized replication origins (Mohl and Gober 1997; Figge et al. 2003; Thanbichler and Shapiro 2006; Toro et al. 2008). Once segregation is finished, ParB additionally interacts with the scaffolding protein PopZ, thereby mediating attachment of the segregated origin regions at the cell poles (Bowman et al. 2008; Ebersbach et al. 2008).

Newborn C. crescentus cells contain a single chromosome, which extends throughout the whole cell, with its replication origin being attached to the old cell pole (Jensen and Shapiro 1999). On entry into S-phase, the parScontaining segment is among the first chromosomal regions to be duplicated. The two copies immediately reassociate with ParB and 
M. Thanbichler

then move apart in a ParA-dependent manner (Thanbichler and Shapiro 2006; Toro et al. 2008; Shebelut et al. 2009). During this partitioning process, one of the sister origin regions remains at its original location, whereas the other one moves rapidly across the cell toward the opposite cell pole (Viollier et al. 2004). MipZ directly interacts with ParB and thus follows the movement of the origin regions (Thanbichler and Shapiro 2006) (Fig. 4). However, it is not stably tethered to the cell poles but rather distributed in a gradient, with its concentration progressively increasing toward the polar ParB - parS nucleoprotein complexes. In vitro studies showed that MipZ acts as an inhibitor of FtsZ polymerization (Thanbichler and Shapiro 2006). Accordingly, FtsZ is consistently localized to the subcellular region that exhibits the lowest concentration of MipZ. Before the start of chromosome replication, the MipZ - ParB complex resides at the old pole, resulting in the accumulation of FtsZ at the opposite end of the cell. However, on duplication and segregation of the origin regions, this polar FtsZ cluster is disassembled and a new one is formed at the cell center (Thanbichler and Shapiro 2006). Synthesis of other celldivision proteins, which occurs later in the C. crescentus cell cycle, may then lead to reorganization of these polymers into a septal ring that can establish a functional divisome and initiate cytokinesis (Sackett et al. 1998; Laub et al. 2000). MipZ thus serves as a molecular ruler that uses the two segregated origin regions as landmarks to determine the cell center, ensuring that the cell constricts in between the two nascent daughter nucleoids.

It is unknown why most $\alpha$-proteobacteria use MipZ instead of the Min or nucleoid occlusion system to regulate division site placement. Conversely, however, a MipZ-based mechanism is clearly not applicable to organisms such as $E$. coli and B. subtilis, which allow overlapping replication cycles and thus accumulate multiple origin regions within a single cell. Thus, bacteria may have evolved a variety of regulatory mechanisms to control divisome assembly that are specifically tailored to their distinct structural and physiological needs.
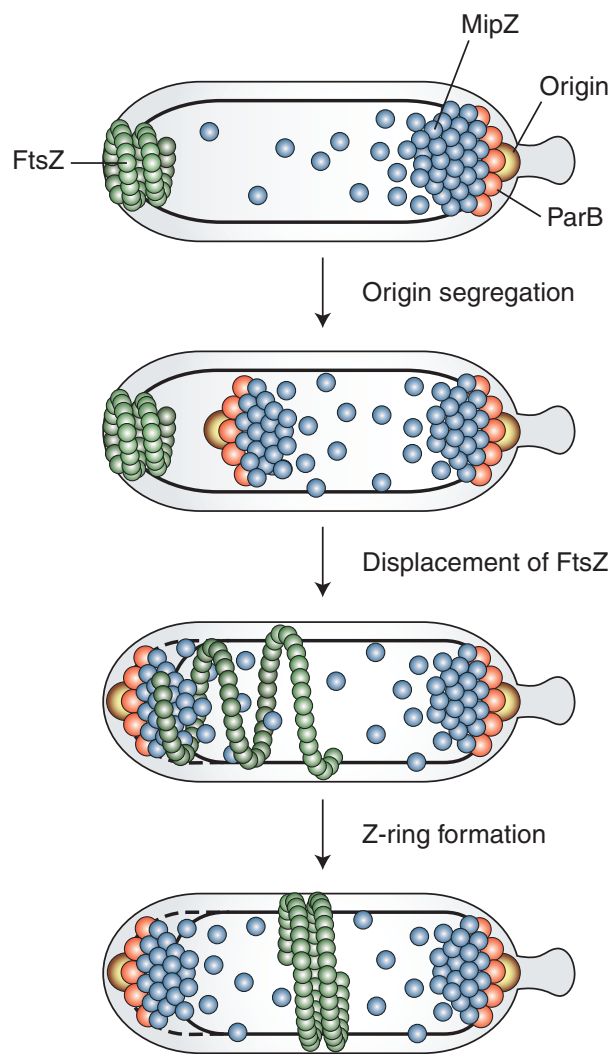

Figure 4. Division site placement by the MipZ - ParB system. The cell division regulator MipZ forms a complex with the DNA-binding protein ParB close to the chromosomal origin of replication, located at the stalked pole of the cell. FtsZ, by contrast, assembles into a polymer that is localized to the pole opposite the stalk. Chromosome replication generates two copies of the origin region, which immediately reassociate with the MipZ - ParB complex and then move apart toward the cell poles. As a consequence, a gradient of MipZ is established, with its concentration being highest in proximity of the two segregated origin regions and lowest at midcell. Owing to the inhibitory effect of MipZ on FtsZ polymerization, the polar FtsZ complex disintegrates and a new polymer is formed at the cell center (adapted from Thanbichler and Shapiro 2006).

\section{FUTURE PERSPECTIVES}

Although considerable advances have been made in understanding the mechanisms that interface chromosome dynamics and cell division in bacteria, many questions remain to be answered. 
Importantly, the pathways that control the frequency of origin firing in E. coli and B. subtilis are still obscure. Furthermore, the biochemical basis for the inhibition of divisome assembly by nucleoid occlusion proteins and for the establishment of the MipZ gradient requires further investigation. It will be interesting to see how widespread the systems identified in the common model organisms are among other bacterial species and what kind of variations have evolved on these schemes. Given the enormous diversity of bacteria and the small number of phyla that are currently studied at the molecular biological level, our current knowledge on bacterial cell biology likely represents only a small piece of the overall picture. Thanks to the increasing ease of whole genome sequencing, transcriptome analyses, and high-throughput ORF cloning, the development of new model systems may become more straightforward in the near future. It will be fascinating to follow the progress of the field and see the surprises that still await discovery.

\section{ACKNOWLEDGMENTS}

This work was supported by the Max Planck Society and a Young Investigator Grant from the Human Frontier Science Program (HFSP).

\section{REFERENCES}

Adams DE, Shekhtman EM, Zechiedrich EL, Schmid MB, Cozzarelli NR. 1992. The role of topoisomerase IV in partitioning bacterial replicons and the structure of catenated intermediates in DNA replication. Cell 71: 277-288.

Anderson DE, Gueiros-Filho FJ, Erickson HP. 2004 Assembly dynamics of FtsZ rings in Bacillus subtilis and Escherichia coli and effects of FtsZ-regulating proteins. J Bacteriol 186: 5775-5781.

Aussel L, Barre FX, Aroyo M, Stasiak A, Stasiak AZ, Sherratt D. 2002. FtsK is a DNA motor protein that activates chromosome dimer resolution by switching the catalytic state of the XerC and XerD recombinases. Cell 108: 195-205.

Barre FX, Aroyo M, Colloms SD, Helfrich A, Cornet F, Sherratt DJ. 2000. FtsK functions in the processing of a Holliday junction intermediate during bacterial chromosome segregation. Genes Dev 14: 2976-2988.

Bastedo DP, Marczynski GT. 2009. CtrA response regulator binding to the Caulobacter chromosome replication origin is required during nutrient and antibiotic stress as well as during cell cycle progression. Mol Microbiol 72: $139-154$.

Bates D. 2008. The bacterial replisome: Back on track? Mol Microbiol 69: 1341-1348.

Bath J, Wu LJ, Errington J, Wang JC. 2000. Role of Bacillus subtilis SpoIIIE in DNA transport across the mother cellprespore division septum. Science 290: 995-997.

Begg KJ, Dewar SJ, Donachie WD. 1995. A new Escherichia coli cell division gene, ftsK. J Bacteriol 177: 6211-6222.

Bernhardt TG, de Boer PA. 2005. SlmA, a nucleoid-associated, FtsZ binding protein required for blocking septal ring assembly over chromosomes in E. coli. Mol Cell 18: 555-564.

Bi EF, Lutkenhaus J. 1991. FtsZ ring structure associated with division in Escherichia coli. Nature 354: 161-164.

Bigot S, Saleh OA, Cornet F, Allemand JF, Barre FX. 2006. Oriented loading of FtsK on KOPS. Nat Struct Mol Biol 13: $1026-1028$.

Bigot S, Saleh OA, Lesterlin C, Pages C, El Karoui M, Dennis C, Grigoriev M, Allemand JF, Barre FX, Cornet F. 2005. KOPS: DNA motifs that control E. coli chromosome segregation by orienting the FtsK translocase. EMBO J 24: 3770-3780.

Biondi EG, Reisinger SJ, Skerker JM, Arif M, Perchuk BS, Ryan KR, Laub MT. 2006. Regulation of the bacterial cell cycle by an integrated genetic circuit. Nature 444: 899-904.

Blakely G, May G, McCulloch R, Arciszewska LK, Burke M, Lovett ST, Sherratt DJ. 1993. Two related recombinases are required for site-specific recombination at dif and cer in E. coli K12. Cell 75: 351-361.

Bowman GR, Comolli LR, Zhu J, Eckart M, Koenig M, Downing KH, Moerner WE, Earnest T, Shapiro L. 2008. A polymeric protein anchors the chromosomal origin/ ParB complex at a bacterial cell pole. Cell 134: 945-955.

Bramkamp M, Emmins R, Weston L, Donovan C, Daniel RA, Errington J. 2008. A novel component of the division-site selection system of Bacillus subtilis and a new mode of action for the division inhibitor MinCD. Mol Microbiol 70: 1556-1569.

Brassinga AK, Siam R, McSween W, Winkler H, Wood D, Marczynski GT. 2002. Conserved response regulator CtrA and IHF binding sites in the $\alpha$-proteobacteria Caulobacter crescentus and Rickettsia prowazekii chromosomal replication origins. J Bacteriol 184: 5789-5799.

Britton RA, Lin DC, Grossman AD. 1998. Characterization of a prokaryotic SMC protein involved in chromosome partitioning. Genes Dev 12: 1254-1259.

Capiaux H, Lesterlin C, Perals K, Louarn JM, Cornet F. 2002. A dual role for the FtsK protein in Escherichia coli chromosome segregation. EMBO Rep 3: 532-536.

Cha JH, Stewart GC. 1997. The divIVA minicell locus of Bacillus subtilis. J Bacteriol 179: 1671-1683.

Collier J, Shapiro L. 2009. Feedback control of DnaAmediated replication initiation by replisome-associated HdaA protein in Caulobacter. J Bacteriol 191: 5706-5716.

Cooper S, Helmstetter CE. 1968. Chromosome replication and the division cycle of Escherichia coli B/r. J Mol Biol 31: $519-540$. 
M. Thanbichler

De Boer PA, Crossley RE, Rothfield LI. 1989. A division inhibitor and a topological specificity factor coded for by the minicell locus determine proper placement of the division septum in E. coli. Cell 56: 641-649.

Degnen ST, Newton A. 1972. Chromosome replication during development in Caulobacter crescentus. J Mol Biol 64: 671-680.

Domian IJ, Quon KC, Shapiro L. 1997. Cell type-specific phosphorylation and proteolysis of a transcriptional regulator controls the G1-to-S transition in a bacterial cell cycle. Cell 90: 415-424.

Ebersbach G, Briegel A, Jensen GJ, Jacobs-Wagner C. 2008. A self-associating protein critical for chromosome attachment, division, and polar organization in Caulobacter. Cell 134: 956-968.

Edwards DH, Errington J. 1997. The Bacillus subtilis DivIVA protein targets to the division septum and controls the site specificity of cell division. Mol Microbiol 24: 905-915.

Espeli O, Lee C, Marians KJ. 2003a. A physical and functional interaction between Escherichia coli FtsK and topoisomerase IV. J Biol Chem 278: 44639-44644.

Espeli O, Levine C, Hassing H, Marians KJ. 2003b. Temporal regulation of topoisomerase IV activity in E. coli. Mol Cell 11: 189-201.

Figge RM, Easter J, Gober JW. 2003. Productive interaction between the chromosome partitioning proteins ParA and ParB, is required for the progression of the cell cycle in Caulobacter crescentus. Mol Microbiol 47: 1225- 1237.

Goehring NW, Beckwith J. 2005. Diverse paths to midcell: Assembly of the bacterial cell division machinery. Curr Biol 15: R514-526.

Gorbatyuk B, Marczynski GT. 2005. Regulated degradation of chromosome replication proteins DnaA and CtrA in Caulobacter crescentus. Mol Microbiol 55: 1233-1245.

Gordon GS, Sitnikov D, Webb CD, Teleman A, Straight A, Losick R, Murray AW, Wright A. 1997. Chromosome and low copy plasmid segregation in E. coli: Visual evidence for distinct mechanisms. Cell 90: 1113-1121.

Grainge I, Bregu M, Vazquez M, Sivanathan V, Ip SC, Sherratt DJ. 2007. Unlinking chromosome catenanes in vivo by site-specific recombination. EMBO J 26: 4228-4238.

Grainge I, Sherratt DJ. 1999. Xer site-specific recombination. DNA strand rejoining by recombinase XerC. J Biol Chem 274: 6763-6769.

Graumann PL. 2007. Cytoskeletal elements in bacteria. Annu Rev Microbiol 61: 589-618.

Gregory JA, Becker EC, Pogliano K. 2008. Bacillus subtilis MinC destabilizes FtsZ-rings at new cell poles and contributes to the timing of cell division. Genes Dev 22: 3475-3488.

Hale CA, Meinhardt H, de Boer PA. 2001. Dynamic localization cycle of the cell division regulator MinE in Escherichia coli. EMBO J 20: 1563-1572.

Hecht GB, Lane T, Ohta N, Sommer JM, Newton A. 1995. An essential single domain response regulator required for normal cell division and differentiation in Caulobacter crescentus. EMBO J 14: 3915-3924.

Hirano T. 2006. At the heart of the chromosome: SMC proteins in action. Nat Rev Mol Cell Biol 7: 311-322.
Hu Z, Lutkenhaus J. 1999. Topological regulation of cell division in Escherichia coli involves rapid pole to pole oscillation of the division inhibitor MinC under the control of MinD and MinE. Mol Microbiol 34: 82-90.

Hu Z, Mukherjee A, Pichoff S, Lutkenhaus J. 1999. The MinC component of the division site selection system in Escherichia coli interacts with FtsZ to prevent polymerization. Proc Natl Acad Sci 96: 14819-14824.

Iniesta AA, Shapiro L. 2008. A bacterial control circuit integrates polar localization and proteolysis of key regulatory proteins with a phospho-signaling cascade. Proc Natl Acad Sci 105: 16602-16607.

Iniesta AA, McGrath PT, Reisenauer A, McAdams HH, Shapiro L. 2006. A phospho-signaling pathway controls the localization and activity of a protease complex critical for bacterial cell cycle progression. Proc Natl Acad Sci 103: 10935-10940.

Ioannidis P, Hotopp JC, Sapountzis P, Siozios S, Tsiamis G, Bordenstein SR, Baldo L, Werren JH, Bourtzis K. 2007. New criteria for selecting the origin of DNA replication in Wolbachia and closely related bacteria. BMC Genomics 8: 182.

Ip SC, Bregu M, Barre FX, Sherratt DJ. 2003. Decatenation of DNA circles by FtsK-dependent Xer site-specific recombination. EMBO J 22: 6399-6407.

Jacobs C, Hung D, Shapiro L. 2001. Dynamic localization of a cytoplasmic signal transduction response regulator controls morphogenesis during the Caulobacter cell cycle. Proc Natl Acad Sci 98: 4095-4100.

Jensen RB, Shapiro L. 1999. The Caulobacter crescentus smc gene is required for cell cycle progression and chromosome segregation. Proc Natl Acad Sci 96: $10661-10666$.

Kaguni JM. 2006. DnaA: Controlling the initiation of bacterial DNA replication and more. Annu Rev Microbiol 60: $351-375$.

Kato J, Nishimura Y, Imamura R, Niki H, Hiraga S, Suzuki H. 1990. New topoisomerase essential for chromosome segregation in E. coli. Cell 63: 393-404.

Kennedy SP, Chevalier F, Barre FX. 2008. Delayed activation of Xer recombination at dif by FtsK during septum assembly in Escherichia coli. Mol Microbiol 68: 10181028.

Lam H, Matroule JY, Jacobs-Wagner C. 2003. The asymmetric spatial distribution of bacterial signal transduction proteins coordinates cell cycle events. Dev Cell 5: $149-159$.

Lau IF, Filipe SR, Soballe B, Okstad OA, Barre FX, Sherratt DJ. 2003. Spatial and temporal organization of replicating Escherichia coli chromosomes. Mol Microbiol 49: $731-743$.

Laub MT, Shapiro L, McAdams HH. 2007. Systems biology of Caulobacter. Annu Rev Genet 41: 429-441.

Laub MT, Chen SL, Shapiro L, McAdams HH. 2002. Genes directly controlled by CtrA, a master regulator of the Caulobacter cell cycle. Proc Natl Acad Sci 99: 46324637.

Laub MT, McAdams HH, Feldblyum T, Fraser CM, Shapiro L. 2000. Global analysis of the genetic network controlling a bacterial cell cycle. Science 290: 2144-2148. 
Leonard AC, Grimwade JE. 2009. Initiating chromosome replication in E. coli: It makes sense to recycle. Genes Dev 23: 1145-1150.

Lesterlin C, Barre FX, Cornet F. 2004. Genetic recombination and the cell cycle: What we have learned from chromosome dimers. Mol Microbiol 54: 1151-1160.

Levy O, Ptacin JL, Pease PJ, Gore J, Eisen MB, Bustamante C, Cozzarelli NR. 2005. Identification of oligonucleotide sequences that direct the movement of the Escherichia coli FtsK translocase. Proc Natl Acad Sci 102: 17618-17623.

Li Z, Trimble MJ, Brun YV, Jensen GJ. 2007. The structure of FtsZ filaments in vivo suggests a force-generating role in cell division. EMBO J 26: 4694-4708.

Liu G, Draper GC, Donachie WD. 1998. FtsK is a bifunctional protein involved in cell division and chromosome localization in Escherichia coli. Mol Microbiol 29: 893-903.

Lowe J, Amos LA. 1998. Crystal structure of the bacterial cell-division protein FtsZ. Nature 391: 203-206.

Luijsterburg MS, Noom MC, Wuite GJ, Dame RT. 2006. The architectural role of nucleoid-associated proteins in the organization of bacterial chromatin: A molecular perspective. J Struct Biol 156: 262-272.

Marczynski GT, Shapiro L. 2002. Control of chromosome replication in Caulobacter crescentus. Annu Rev Microbiol 56: $625-656$.

Margolin W. 2001. Spatial regulation of cytokinesis in bacteria. Curr Opin Microbiol 4: 647-652.

Marston AL, Thomaides HB, Edwards DH, Sharpe ME, Errington J. 1998. Polar localization of the MinD protein of Bacillus subtilis and its role in selection of the mid-cell division site. Genes Dev 12: 3419-3430.

Massey TH, Aussel L, Barre FX, Sherratt DJ. 2004. Asymmetric activation of Xer site-specific recombination by FtsK. EMBO Rep 5: 399-404.

Massey TH, Mercogliano CP, Yates J, Sherratt DJ, Lowe J. 2006. Double-stranded DNA translocation: Structure and mechanism of hexameric FtsK. Mol Cell 23: 457469.

Matroule JY, Lam H, Burnette DT, Jacobs-Wagner C. 2004. Cytokinesis monitoring during development: Rapid pole-to-pole shuttling of a signaling protein by localized kinase and phosphatase in Caulobacter. Cell 118: 579-590.

McGrath PT, Iniesta AA, Ryan KR, Shapiro L, McAdams HH. 2006. A dynamically localized protease complex and a polar specificity factor control a cell cycle master regulator. Cell 124: 535-547.

Michie KA, Lowe J. 2006. Dynamic filaments of the bacterial cytoskeleton. Annu Rev Biochem 75: 467-492.

Mohl DA, Gober JW. 1997. Cell cycle-dependent polar localization of chromosome partitioning proteins in Caulobacter crescentus. Cell 88: 675-684.

Morris DM, Jensen GJ. 2008. Toward a biomechanical understanding of whole bacterial cells. Annu Rev Biochem 77: $583-613$.

Mott ML, Berger JM. 2007. DNA replication initiation: Mechanisms and regulation in bacteria. Nat Rev Microbiol 5: 343-354.

Mukherjee A, Lutkenhaus J. 1998. Dynamic assembly of FtsZ regulated by GTP hydrolysis. EMBO J 17: 462-469.
Mulder E, Woldringh CL. 1989. Actively replicating nucleoids influence positioning of division sites in Escherichia coli filaments forming cells lacking DNA. J Bacteriol 171: 4303-4314.

Nielsen HJ, Li Y, Youngren B, Hansen FG, Austin S. 2006. Progressive segregation of the Escherichia coli chromosome. Mol Microbiol 61: 383-393.

Nielsen HJ, Youngren B, Hansen FG, Austin S. 2007. Dynamics of Escherichia coli chromosome segregation during multifork replication. J Bacteriol 189: 8660-8666.

Niki H, Hiraga S. 1998. Polar localization of the replication origin and terminus in Escherichia coli nucleoids during chromosome partitioning. Genes Dev 12: 1036-1045.

Niki H, Yamaichi Y, Hiraga S. 2000. Dynamic organization of chromosomal DNA in Escherichia coli. Genes Dev 14: 212-223.

O'Donnell M. 2006. Replisome architecture and dynamics in Escherichia coli. J Biol Chem 281: 10653-10656.

Ohta N, Lane T, Ninfa EG, Sommer JM, Newton A. 1992. A histidine protein kinase homologue required for regulation of bacterial cell division and differentiation. Proc Natl Acad Sci 89: 10297-10301.

Osawa M, Anderson DE, Erickson HP. 2008. Reconstitution of contractile FtsZ rings in liposomes. Science 320: 792 794.

Patrick JE, Kearns DB. 2008. MinJ (YvjD) is a topological determinant of cell division in Bacillus subtilis. Mol Microbiol 70: 1166-1179.

Paul R, Jaeger T, Abel S, Wiederkehr I, Folcher M, Biondi EG, Laub MT, Jenal U. 2008. Allosteric regulation of histidine kinases by their cognate response regulator determines cell fate. Cell 133: 452-461.

Pease PJ, Levy O, Cost GJ, Gore J, Ptacin JL, Sherratt D, Bustamante C, Cozzarelli NR. 2005. Sequence-directed DNA translocation by purified FtsK. Science 307: 586590.

Peng H, Marians KJ. 1993. Decatenation activity of topoisomerase IV during oriC and pBR322 DNA replication in vitro. Proc Natl Acad Sci 90: 8571-8575.

Perals K, Cornet F, Merlet Y, Delon I, Louarn JM. 2000. Functional polarization of the Escherichia coli chromosome terminus: The dif site acts in chromosome dimer resolution only when located between long stretches of opposite polarity. Mol Microbiol 36: 33-43.

Peters PC, Migocki MD, Thoni C, Harry EJ. 2007. A new assembly pathway for the cytokinetic $\mathrm{Z}$ ring from a dynamic helical structure in vegetatively growing cells of Bacillus subtilis. Mol Microbiol 64: 487-499.

Postow L, Hardy CD, Arsuaga J, Cozzarelli NR. 2004 Topological domain structure of the Escherichia coli chromosome. Genes Dev 18: 1766-1779.

Ptacin JL, Nollmann M, Becker EC, Cozzarelli NR, Pogliano K, Bustamante C. 2008. Sequence-directed DNA export guides chromosome translocation during sporulation in Bacillus subtilis. Nat Struct Mol Biol 15: 485-493.

Ptacin JL, Nollmann M, Bustamante C, Cozzarelli NR. 2006. Identification of the FtsK sequence-recognition domain. Nat Struct Mol Biol 13: 1023-1025.

Quon KC, Marczynski GT, Shapiro L. 1996. Cell cycle control by an essential bacterial two-component signal transduction protein. Cell 84: 83-93. 
M. Thanbichler

Quon KC, Yang B, Domian IJ, Shapiro L, Marczynski GT. 1998. Negative control of bacterial DNA replication by a cell cycle regulatory protein that binds at the chromosome origin. Proc Natl Acad Sci 95: 120-125.

Radhakrishnan SK, Thanbichler M, Viollier PH. 2008. The dynamic interplay between a cell fate determinant and a lysozyme homolog drives the asymmetric division cycle of Caulobacter crescentus. Genes Dev 22: 212-225.

Raskin DM, de Boer PA. 1999a. MinDE-dependent poleto-pole oscillation of division inhibitor MinC in Escherichia coli. J Bacteriol 181: 6419-6424.

Raskin DM, de Boer PA. 1999b. Rapid pole-to-pole oscillation of a protein required for directing division to the middle of Escherichia coli. Proc Natl Acad Sci 96: 4971-4976.

Reyes-Lamothe R, Wang X, Sherratt D. 2008b. Escherichia coli and its chromosome. Trends Microbiol 16: 238-245.

Reyes-Lamothe R, Possoz C, Danilova O, Sherratt DJ. 2008a. Independent positioning and action of Escherichia coli replisomes in live cells. Cell 133: 90-102.

Rothfield L, Taghbalout A, Shih YL. 2005. Spatial control of bacterial division-site placement. Nat Rev Microbiol 3: 959-968.

Sackett MJ, Kelly AJ, Brun YV. 1998. Ordered expression of $f t s Q A$ and $f t s Z$ during the Caulobacter crescentus cell cycle. Mol Microbiol 28: 421-434.

Saleh OA, Perals C, Barre FX, Allemand JF. 2004. Fast, DNA-sequence independent translocation by FtsK in a single-molecule experiment. EMBO J 23: 2430-2439.

Schvartzman JB, Stasiak A. 2004. A topological view of the replicon. EMBO Rep 5: 256-261.

Shaheen SM, Ouimet MC, Marczynski GT. 2009. Comparative analysis of Caulobacter chromosome replication origins. Microbiology 155: 1215-1225.

Shebelut CW, Jensen RB, Gitai Z. 2009. Growth conditions regulate the requirements for Caulobacter chromosome segregation. J Bacteriol 191: 1097-1100.

Shih YL, Rothfield L. 2006. The bacterial cytoskeleton. Microbiol Mol Biol Rev 70: 729-754.

Siam R, Marczynski GT. 2000. Cell cycle regulator phosphorylation stimulates two distinct modes of binding at a chromosome replication origin. EMBO J 19: 1138-1147.

Siam R, Brassinga AK, Marczynski GT. 2003. A dual binding site for integration host factor and the response regulator CtrA inside the Caulobacter crescentus replication origin. J Bacteriol 185: 5563-5572.

Sivanathan V, Allen MD, de Bekker C, Baker R, Arciszewska LK, Freund SM, Bycroft M, Lowe J, Sherratt DJ. 2006. The FtsK $\gamma$ domain directs oriented DNA translocation by interacting with KOPS. Nat Struct Mol Biol 13: 965-972.

Steiner WW, Kuempel PL. 1998. Sister chromatid exchange frequencies in Escherichia coli analyzed by recombination at the dif resolvase site. J Bacteriol 180: 6269-6275.

Teleman AA, Graumann PL, Lin DC, Grossman AD, Losick R. 1998. Chromosome arrangement within a bacterium. Curr Biol 8: 1102-1109.

Thanbichler M. 2009. Closing the ring: A new twist to bacterial chromosome condensation. Cell 137: 598-600.
Thanbichler M, Shapiro L. 2006. MipZ, a spatial regulator coordinating chromosome segregation with cell division in Caulobacter. Cell 126: 147-162.

Thanbichler M, Shapiro L. 2008. Getting organized-how bacterial cells move proteins and DNA. Nat Rev Microbiol 6: $28-40$.

Thanbichler M, Wang SC, Shapiro L. 2005. The bacterial nucleoid: A highly organized and dynamic structure. J Cell Biochem 96: 506-521.

Thanedar S, Margolin W. 2004. FtsZ exhibits rapid movement and oscillation waves in helix-like patterns in Escherichia coli. Curr Biol 14: 1167-1173.

Toro E, Hong SH, McAdams HH, Shapiro L. 2008. Caulobacter requires a dedicated mechanism to initiate chromosome segregation. Proc Natl Acad Sci 105: 15435-15440.

Ullsperger C, Cozzarelli NR. 1996. Contrasting enzymatic activities of topoisomerase IV and DNA gyrase from Escherichia coli. J Biol Chem 271: 31549-31555.

Viollier PH, Sternheim N, Shapiro L. 2002. Identification of a localization factor for the polar positioning of bacterial structural and regulatory proteins. Proc Natl Acad Sci 99: 13831-13836.

Viollier PH, Thanbichler M, McGrath PT, West L, Meewan M, McAdams HH, Shapiro L. 2004. Rapid and sequential movement of individual chromosomal loci to specific subcellular locations during bacterial DNA replication. Proc Natl Acad Sci 101: 9257-9262.

Wang L, Lutkenhaus J. 1998. FtsK is an essential cell division protein that is localized to the septum and induced as part of the SOS response. Mol Microbiol 29: 731-740.

Wang SC, Shapiro L. 2004. The topoisomerase IV ParC subunit colocalizes with the Caulobacter replisome and is required for polar localization of replication origins. Proc Natl Acad Sci 101: 9251-9256.

Wang SC, West L, Shapiro L. 2006a. The bifunctional FtsK protein mediates chromosome partitioning and cell division in Caulobacter. J Bacteriol 188: 1497-1508.

Wang X, Liu X, Possoz C, Sherratt DJ. 2006b. The two Escherichia coli chromosome arms locate to separate cell halves. Genes Dev 20: 1727-1731.

Webb CD, Graumann PL, Kahana JA, Teleman AA, Silver PA, Losick R. 1998. Use of time-lapse microscopy to visualize rapid movement of the replication origin region of the chromosome during the cell cycle in Bacillus subtilis. Mol Microbiol 28: 883-892.

Wheeler RT, Shapiro L. 1999. Differential localization of two histidine kinases controlling bacterial cell differentiation. Mol Cell 4: 683-694.

Woldringh CL, Mulder E, Valkenburg JA, Wientjes FB, Zaritsky A, Nanninga N. 1990. Role of the nucleoid in the toporegulation of division. Res Microbiol 141:39-49.

Wu LJ, Errington J. 1994. Bacillus subtilis SpoIIIE protein required for DNA segregation during asymmetric cell division. Science 264: 572-575.

Wu LJ, Errington J. 1997. Septal localization of the SpoIIIE chromosome partitioning protein in Bacillus subtilis. EMBO J 16: 2161-2169.

Wu LJ, Errington J. 2004. Coordination of cell division and chromosome segregation by a nucleoid occlusion protein in Bacillus subtilis. Cell 117: 915-925. 
Coordination of DNA Replication and Cell Division

Wu J, Ohta N, Newton A. 1998. An essential, multicomponent signal transduction pathway required for cell cycle regulation in Caulobacter. Proc Natl Acad Sci 95: 1443-1448.

Wu LJ, Ishikawa S, Kawai Y, Oshima T, Ogasawara N, Errington J. 2009. Noc protein binds to specific DNA sequences to coordinate cell division with chromosome segregation. EMBO J 28: 1940-1952.

Yates J, Zhekov I, Baker R, Eklund B, Sherratt DJ, Arciszewska LK. 2006. Dissection of a functional interaction between the DNA translocase, FtsK, and the XerD recombinase. Mol Microbiol 59: 1754-1766.

Yu XC, Margolin W. 1999. FtsZ ring clusters in min and partition mutants: Role of both the Min system and the nucleoid in regulating FtsZ ring localization. Mol Microbiol 32: 315-326.
Yu XC, Weihe EK, Margolin W. 1998b. Role of the C terminus of FtsK in Escherichia coli chromosome segregation. J Bacteriol 180: 6424-6428.

Yu XC, Tran AH, Sun Q, Margolin W. 1998a. Localization of cell division protein FtsK to the Escherichia coli septum and identification of a potential $\mathrm{N}$-terminal targeting domain. J Bacteriol 180: 1296-1304.

Zakrzewska-Czerwinska J, Jakimowicz D, Zawilak-Pawlik A, Messer W. 2007. Regulation of the initiation of chromosomal replication in bacteria. FEMS Microbiol Rev 31: 378-387.

Zechiedrich EL, Cozzarelli NR. 1995. Roles of topoisomerase IV and DNA gyrase in DNA unlinking during replication in Escherichia coli. Genes Dev 9: 2859-2869. 


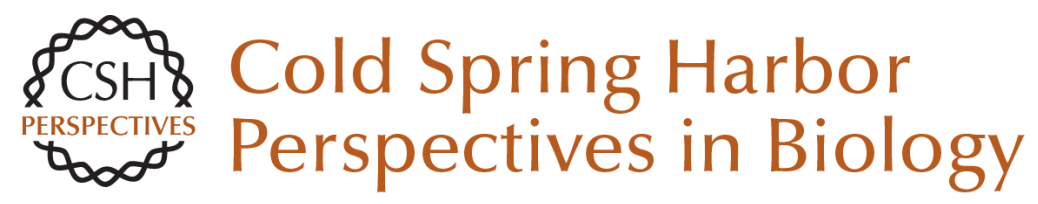

\section{Synchronization of Chromosome Dynamics and Cell Division in Bacteria}

\section{Martin Thanbichler}

Cold Spring Harb Perspect Biol 2010; doi: 10.1101/cshperspect.a000331 originally published online November 18, 2009

\section{Subject Collection Cell Biology of Bacteria}

\section{Electron Cryotomography}

Elitza I. Tocheva, Zhuo Li and Grant J. Jensen

\section{Protein Subcellular Localization in Bacteria} David Z. Rudner and Richard Losick

Poles Apart: Prokaryotic Polar Organelles and Their Spatial Regulation

Clare L. Kirkpatrick and Patrick H. Viollier

Myxobacteria, Polarity, and Multicellular Morphogenesis

Dale Kaiser, Mark Robinson and Lee Kroos

Membrane-associated DNA Transport Machines Briana Burton and David Dubnau

The Bacterial Cell Envelope Thomas J. Silhavy, Daniel Kahne and Suzanne Walker

Cell Biology of Prokaryotic Organelles Dorothee Murat, Meghan Byrne and Arash Komeili

Bacterial Chromosome Organization and Segregation

Esteban Toro and Lucy Shapiro
Cyanobacterial Heterocysts

Krithika Kumar, Rodrigo A. Mella-Herrera and James W. Golden

Synchronization of Chromosome Dynamics and Cell Division in Bacteria Martin Thanbichler

Automated Quantitative Live Cell Fluorescence Microscopy Michael Fero and Kit Pogliano

The Structure and Function of Bacterial Actin Homologs Joshua W. Shaevitz and Zemer Gitai

Biofilms Daniel López, Hera Vlamakis and Roberto Kolter

Bacterial Nanomachines: The Flagellum and Type III Injectisome Marc Erhardt, Keiichi Namba and Kelly T. Hughes

Single-Molecule and Superresolution Imaging in Live Bacteria Cells Julie S. Biteen and W.E. Moerner

For additional articles in this collection, see http://cshperspectives.cshlp.org/cgi/collection/

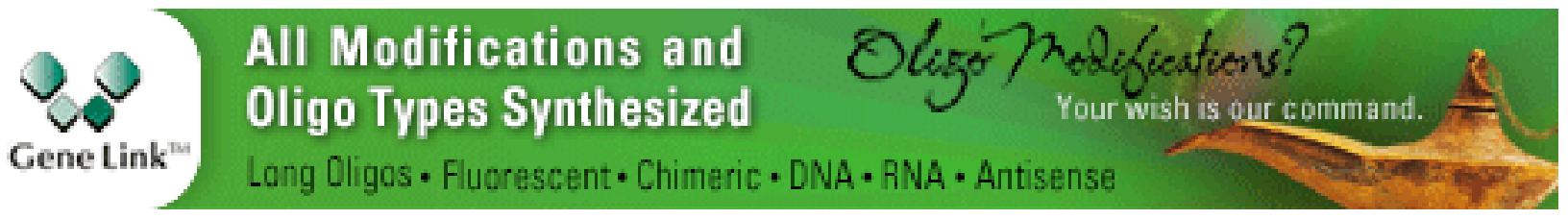

